\title{
Obsessive-Compulsive Behavior Disappearing after Left Capsular Genu Infarction
}

\author{
Ji-Hyang Oha Bo-Young Ahn ${ }^{a}$ Min-Kyung Jo ${ }^{a}$ \\ Yeo-Ju Yoon ${ }^{a}$ Kyu-Hyun Park ${ }^{a}$ Duk L. Na ${ }^{b}$ Eun-Joo Kim ${ }^{a}$ \\ a'Department of Neurology, Pusan National University Hospital, Pusan National \\ University School of Medicine and Medical Research Institute, Busan, and \\ ${ }^{b}$ Department of Neurology, Samsung Medical Center, Sungkyunkwan University \\ School of Medicine, Seoul, Korea
}

\section{Key Words}

Obsessive-compulsive behaviour · Capsular genu infarction

\begin{abstract}
This case report describes a 74-year-old woman with obsessive-compulsive behaviors that disappeared following a left capsular genu infarction. The patient's capsular genu infarction likely resulted in thalamocortical disconnection in the cortico-basal gangliathalamocortical loop, which may have caused the disappearance of her obsessivecompulsive symptoms. The fact that anterior capsulotomy has been demonstrated to be effective for treating refractory obsessive-compulsive disorder further supports this hypothesis.
\end{abstract}

\section{Introduction}

Obsessive-compulsive disorder (OCD) is a relatively common, chronic anxiety disorder. OCD is characterized by recurring impulses or intrusive thoughts (obsessions) and repetitive behaviors or mental actions (compulsions) [1]. We report a case of obsessive compulsive behaviors which disappeared after left capsular genu infarction.

\section{Case Report}

A previously healthy 74-year-old woman presented to a neurological clinic with acute onset memory impairment and abnormal behavior 9 days after the onset of symptoms. The patient was unable to remember whether she had eaten breakfast only a few hours after the meal. She had difficulty recalling the names of familiar objects, and responded to every question posed to her by saying that she did not know anything. The patient's family noted that her speech was significantly reduced, and her facial expressions were severely decreased. Despite cognitive deficits and abnormal behaviors, the patient's 
general activities of daily living were relatively well-preserved. The results of a general physical examination were unremarkable. On neurological examination, mild dysarthria and right facial palsy were detected. Laboratory measures, including complete blood count, electrolytes, chemistry and liver function were within normal limits. The patient had been treated with antihypertensive and antidiabetic drugs. She was not prescribed, nor did she take any psychiatric drugs. A detailed neuropsychological evaluation revealed cognitive impairments in the domains of verbal/visual memory, language, and frontal/executive functions. Brain computed tomography (CT) scan was conducted 10 days following

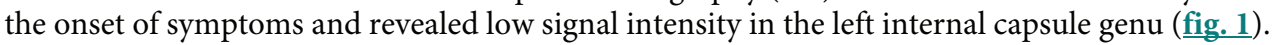

The patient's family reported that she had exhibited obsessive-compulsive behaviors over the past 5 to 6 years. For example, the patient was very meticulous about cleaning, exhibited increased hand washing frequency, and wore white gloves whenever she went out. The patient had also become obsessed with drinking one liter of milk, 5 or 6 bottles of non-narcotic cold medicine, and taking 2 pills of cheongsimhwan, a Korean herbal medicine, every day. Of note, at the time of onset of the patient's presenting symptoms, these obsessive-compulsive behaviors had abruptly ceased. Specifically, she had stopped asking her family for the drinks and pills and no longer engaged in the hand washing behavior. Ten days following her infarction, the patient visited our clinic wearing her white gloves, as usual. However, at a follow-up visit 4 months after the infarction, the patient visited without the gloves and her obsessive-compulsive behaviors remained absent.

\section{Conclusions}

Memory impairments and abnormal behaviors in this patient had developed acutely, along with neurological deficits such as right facial palsy and dysarthria. Brain CT conducted 10 days after onset revealed a left internal capsular genu infarction, which corresponded with her neurological symptoms [2]. As the patient's general physical examination and laboratory results were normal and she did not have any history of psychiatric drug use, her behavioral and cognitive symptoms were unlikely to be due to dehydration, infection, or the use of drugs. Furthermore, the behavioral changes were unlikely to be due to inattention, confusion, or abulia, because nearly all of the obsessivecompulsive behaviors that the patient had displayed prior to her infarction disappeared immediately following the stroke, and these behavioral changes persisted at the 4 month follow-up.

Cheongsimhwan, a traditional Korean herbal medicine, is composed of about 30 different kinds of herbs. This herbal medicine is believed to promote the circulation of the peripheral blood. Although it has been known to have a few effects on the central nervous system, it is unlikely to account for the behavioral and cognitive changes observed in the patient, because the patient had been taking 2 pills of this medicine every day for the past 5-6 years without any problems.

The near complete disappearance of the patient's previous obsessive-compulsive behaviors following her stroke was a most unique observation.

Neural correlates of OCD include the orbitofrontal cortex, caudate, thalamus, and anterior cingulate cortex [3]. Orbitofrontal-subcortical hyperactivity due to an imbalance of direct versus indirect striatopallidal pathway activity has been suggested as a possible pathophysiological mechanism of OCD [4]. ${ }^{18} \mathrm{~F}$-FDG-PET studies have demonstrated more metabolic activity in the orbitofrontal cortexes and caudate nuclei of OCD patients than in healthy controls, as well as decreased metabolic activity in these areas after serotonergic therapy in patients with OCD [5, 6]. Bilateral anterior capsulotomy is a useful surgical procedure for the treatment of refractory OCD [7]. The lesions made to the anterior limb of the internal capsule in this procedure may interrupt reciprocal 
thalamocortical projections, relieving the obsessive-compulsive symptoms attributed to remote cortical damage [8]. Thus, the obsessive-compulsive behaviors observed in our patient may have disappeared due to the thalamocortical disconnection that reduced orbitofrontal-subcortical hyperactivity after capsular genu infarction.

\section{Acknowledgements}

This study was supported by a grant of the Korea Health 21 R\&D Project, Ministry of Health, Welfare, and Family Affairs, Republic of Korea (A050079) and a clinical research grant from Pusan National University Hospital 2010.

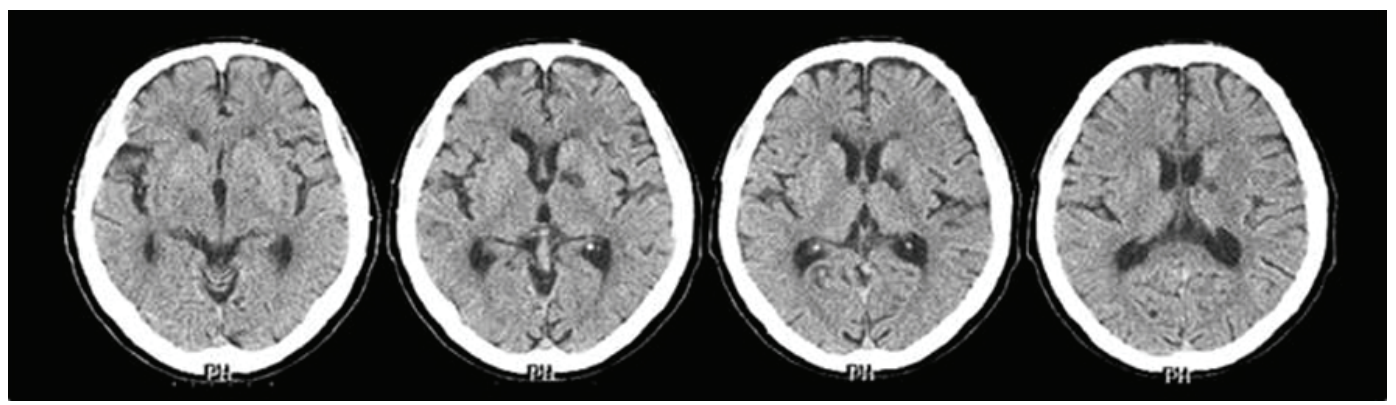

Fig. 1. Axial brain CT images show low signal intensity that was localized to the left internal capsular genu.

\section{References}

- Huey E, Zahn R, Krueger F, Moll J, Kapogiannis D, Wassermann E, Grafman J: A psychological and neuroanatomical model of obsessive-compulsive disorder. J Neuropsychiatry Clin Neurosci 2008;20:390-408.

- Bogousslavsky J, Regli F: Capsular genu syndrome. Neurology 1990;40:1499-1502.

3 Saxena S, Rauch S: Functional neuroimaging and the neuroanatomy of obsessive-compulsive disorder. Psychiatr Clin North Am 2000;23:563-586.

4 Saxena S, Bota R, Brody A: Brain-behavior relationships in obsessive-compulsive disorder. Semin Clin Neuropsychiatry 2001;6:82-101.

5 Baxter LJ, Phelps M, Mazziotta J, Guze B, Schwartz J, Selin C: Local cerebral glucose metabolic rates in obsessive-compulsive disorder. A comparison with rates in unipolar depression and in normal controls. Arch Gen Psychiatry 1987;44:211-218.

-6 Baxter LJ, Saxena S, Brody A, Ackermann R, Colgan M, Schwartz J, Allen-Martinez Z, Fuster J, Phelps M: Brain mediation of obsessive-compulsive disorder symptoms: evidence from functional brain imaging studies in the human and nonhuman primate. Semin Clin Neuropsychiatry 1996;1:32-47.

7 Rück C, Karlsson A, Steele J, Edman G, Meyerson B, Ericson K, Nyman H, Asberg M, Svanborg P: Capsulotomy for obsessive-compulsive disorder: long-term follow-up of 25 patients. Arch Gen Psychiatry 2008;65:914-921.

8 Liu K, Zhang H, Liu C, Guan Y, Lang L, Cheng Y, Sun B, Wang H, Zuo C, Pan L, et al: Stereotactic treatment of refractory obsessive compulsive disorder by bilateral capsulotomy with 3 years follow-up. J Clin Neurosci 2008;15:622-629. 